\title{
DETERMINING THE ASYMMETRIC RUDDER EFFICIENCY OF A TWIN RUDDER PATROL SHIP AT MANOEUVRING
}

\author{
Dobrin EFremov \\ Institute of Metal Science, Equipment and Technologies \\ with Hydro- and Aerodynamics Centre "Acad. Angel Balevski", \\ Bulgarian Academy of Sciences \\ 1, William Froude St., 9003 Varna, Bulgaria, \\ e-mail:d.efremov@bshc.bg
}

\begin{abstract}
Nowadays, large number of newly built inland and navy vessels is equipped with a Twin Propeller-Twin Rudder configuration (TPTR). Observations of the modes of work of each propeller and rudder when performing manoeuvres at curvilinear trajectory show their asymmetrical loading. The nature and parameters of the phenomenon are not sufficiently studied, which in specific manoeuvres could create overloading and loss of effectiveness to some of the units of the TPTR system. To investigate deeply the phenomena of asymmetric load, appropriate manoeuvring experiments with free-running fast patrol ship model are carried out by which the rudder forces are measured. Twinrudder, NACA 0019 profile configuration with different spacing among rudders and its interaction effects was studied by ReynoldsAveraged Navier-Stokes methods. Coefficients for estimating the asymmetric efficiency of the units of the twin-rudder system are developed, also regression formulas are proposed to predict the impact of the spacing on twin-rudder lift coefficient and related conclusions are summarized.
\end{abstract}

Keywords: twin rudder, asymmetric efficiency, manoeuvring, interaction coefficients, lift force, CFD.

\section{INTRODUCTION}

Nowadays, a large number of newly built inland and navy vessels is equipped with a Twin Propeller-Twin Rudder configuration (TPTR). Furthermore, the TPTR is applied to large seagoing ships in order to enhance its performance in manoeuvring, especially in shallow water. When the vessels are equipped with multiple rudders, the interaction effects between the rudders affect to the

DOI: 10.7546/EngSci.LVIII.21.02.03 
hydrodynamic characteristics of each one. In NATO Research Units, criteria and standards for handling of this ship type have been extensively developed [1].

Observations of the work modes of each propeller and rudder when performing manoeuvres at curvilinear trajectory show asymmetrical loading. One of the reasons are the rudder inflow velocity components, also the angle of attack to each rudder. The nature and parameters of the phenomenon are not sufficiently studied, which in specific manoeuvres could create overloading and loss of effectiveness to some of the units of the TR system [2-8].

The purpose of the paper is to study the effectiveness of the ship TR system in manoeuvring, taking into account the specifics of working in oblique flow of the "internally" and "externally" located rudders, respectively, to the trajectory of motion. This research could be helpful in the preliminary design stage of the ship steering systems in order to be improved the effectiveness of the TR system.

To investigate deeply the phenomena of asymmetric load, appropriate manoeuvring experiments with free-running ship model are carried out by which the rudder forces of twin rudder, NACA 0019 profile configuration, are measured. To be predicted the impact of different distances among rudders, regression equations are developed and described by RANS methods. Based on the obtained investigation results, analyses of interaction effects in the TR system and coefficients for estimating the asymmetric efficiency in "open water" of its units are performed.

\section{DESCRIPTION OF THE SYSTEM MODEL OF THE INTERACTION OF THE RUDDERS AT THE TPTR SYSTEM IN SHIP MANOEUVRE}

To analyse the interaction between rudder-propeller-hull, morer attention should be paid to some dependencies affecting to the rudder behaviour $[6$, 9-13]. The stream flow through the rudder or the propeller-rudder system is a wake fraction affected by the hull and propeller. These dependencies are represented by correction coefficients to the rudder lift derivative in the form $[7,10-11,14-15]$ :

$$
C_{Y L}=r_{1} \cdot r_{2} \cdot r_{3} \cdot C_{Y L}^{\delta}\left(\delta-\beta_{k}\right)
$$

Rudder-propeller interaction

- For a rudder located along the shaft axis, a coefficient about the propeller

Engineering Sciences, LVIII, 2021, No. 2 
influence " $r_{1}$ " is:

$$
r_{1}=\frac{Y_{L}}{C_{Y L} \frac{\rho V^{2}}{2} A_{R}}=\frac{A_{R}^{I I}}{A_{R}}+\frac{A_{R}^{I}}{A_{R}}\left(1+\frac{\Delta V}{V}\right)^{2},
$$

where $A_{R}^{I}$ is the rudder area into the propeller flow stream; $A_{R}^{I I}$ - the rest rudder area; $V$ - the flow speed behind the hull; $\Delta V$ - the flow speed into the propeller zone.

Rudder-hull interaction

- In the case of curvilinear motion with a drift angle $\beta$, the character of the hull flow varies, respectively, the wake fraction $w$ [16-21]. The analysis steps in the asymmetric variation of the $w$ in the TPTR system are described in [22-23]. Obviously, in the zone of the TR system due to the interaction with the hull $w$ is modified, which describes the correction " $r_{2}$ ":

$$
r_{2}=\left(1-w_{R}^{L, R}\right)^{2},
$$

where $w_{R}^{L, R}$ is the wake fraction at the twin rudder system, port $(L)$ and starboard $(R)$ side.

Rudder-rudder horn interaction

- The rudder characteristics mainly depend on the aspect ratio of the "Rudderrudder horn" and rudder mean chord. The correction " $r_{3}$ " describes the ratio of the rudder lift force derivatives with horn and without any:

$$
r_{3}=\frac{C_{Y L+K r o n}^{\delta}}{C_{Y L}^{\delta}}
$$

\section{Local drift angle influence}

- The asymmetric load of the TR could be explained by the variation of local drift angle $\beta_{k}$ and wake fraction $w$. The interaction of $\beta$ to $w$ is fundamentally different for both boards. During motion of a TPTR vessel in curved trajectory, the $\beta_{k}$ in the rudder zone is different because of the radii of rotation according to centre of turning due to the rudder position along the ship [2, 8, 23-24].

Furthermore, $w$ depends on the advance coefficient $J$ and also in the TR system is asymmetric, if it is considered separately for each rudder zone. The velocity vectors $V_{\text {port }}, V_{s b}$ at the corresponding location point of the rudders are affected by the angular velocity, Fig. $1[13,20]$ :

$$
r=\frac{V}{R} \text {. }
$$


The described velocity interactions at the point where the rudder is located laterally (on-board) look like:

$$
V_{R}^{p, s b}=V \sqrt{1+\left|r_{z}\right| \cdot\left|L_{R}^{p, s b}\right| \cdot\left(2 \cdot\left(\beta+\delta_{c}\right)+\left|r_{z}\right| \cdot\left|L_{R}^{p, s b}\right|\right)} .
$$

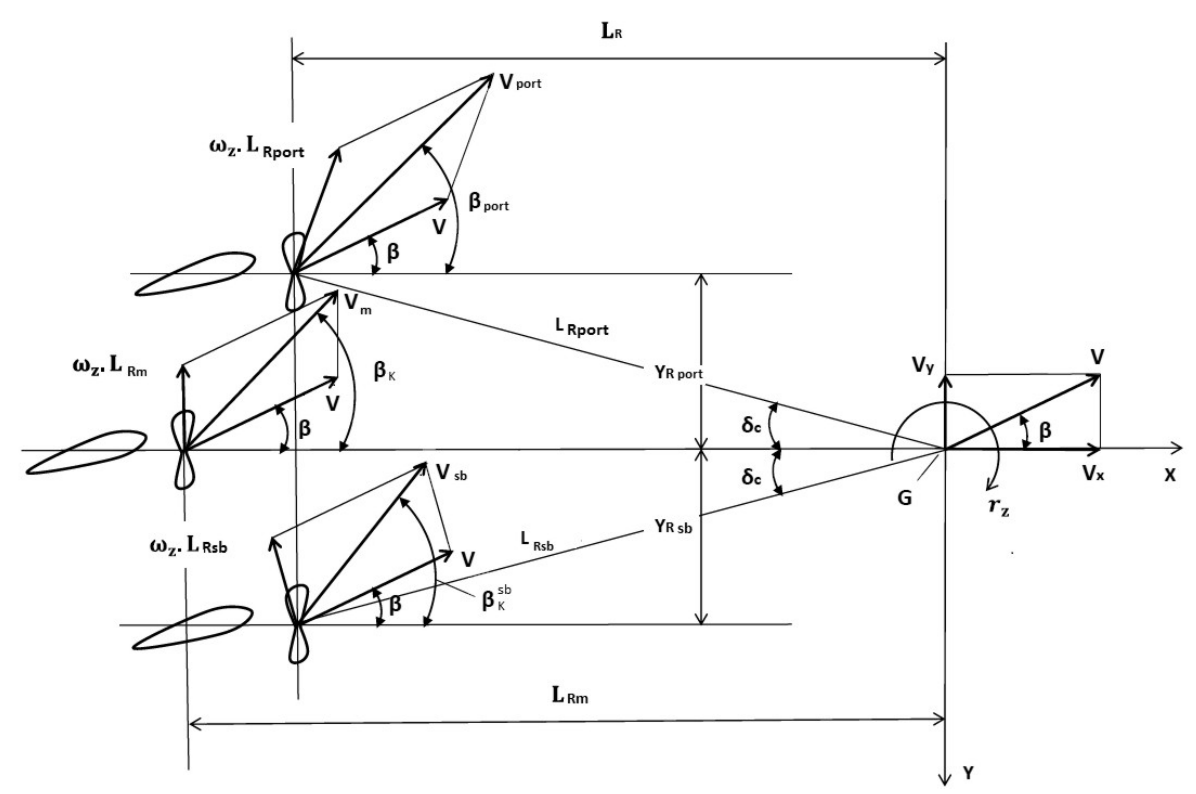

Fig. 1. Interaction between board velocity vectors and angular velocity, ship speed at centre of gravity and local drift angles [22]

The determination of the local drift angle $\beta_{k}$ at a rudder along in the middle line plane and the local velocity $V_{\text {mid }}$ is descibed by [25]. At location different from the middle plane like at TPTR ships, the rudders shifting location must take into account - this distance is determined by the angle $\beta_{c}$, Fig. 1. The described interactions are present in the equation below:

$$
\beta_{k}^{p, s b}=\frac{\beta+\left|r_{z}\right| \cdot\left|L_{R}^{p, s b}\right|}{1 \pm\left|r_{z}\right| \cdot\left|Y_{R}\right|} .
$$

Through the above described equations, the system model of interaction of the rudders at the TPTR system in a curvilinear manoeuvre is presented, and the influence to the efficiency of the TR system, respectively [13, 22]. Based on this description the presented experimental and numerical investigations are conducted. 


\section{FREE-RUNNING MODEL MANOEUVRING TESTS FOR INVESTIGATION OF THE ASYMMETRIC BEHAVIOUR OF THE TR SYSTEM UNITS}

\subsection{Experimental matrix with measurement of the rudder forces and torques of the TR system}

Experimental manoeuvring tests are provided in order to be observed the phenomenon. The dynamics of the Engine-Hull-Propeller system can be modelled in three scenarios. Keeping the RPM constant or the shaft torque, and the latter is to model the engine output power. These considerations led to the choice of simplified set-up with twin Engine-Propeller. Both engines were set to maintain the desired constant revolutions corresponding to the required advance speed, and the effectiveness of the "internal" and "external" rudder is monitored by appropriate dynamometer [2].

The experimental program includes standard turning circle manoeuvres with speeds at which the units of the TR system are subjected to heavy loads and the asymmetrical load can be determined, Table 1. Since the measurement is done in the stock of one of the rudders, the manoeuvres are provided for both boards.

Table 1. Test matrix

\begin{tabular}{|c|c|c|c|}
\hline Manoeuvre & Model initial speed $[\mathrm{m} / \mathrm{s}]$ & Fr $[-]$ & Rudder angle \\
\hline Turning & $1.9 ; 2.48$ & $0.34 ; 0.44$ & $\pm 25 ; 30 ; 35$ \\
\hline
\end{tabular}

Ship model

A fast TPTR patrol vessel model is used for the experimental investigation. It is designed and produced at BSHC. Model hull main ratios are given in Table 2, and 3D hull view in Fig. 2. The model rudders (Fig. 3) are with characteristics given in Table 3 . The TRTP arrangement on the model is illustrated in Fig. 4.

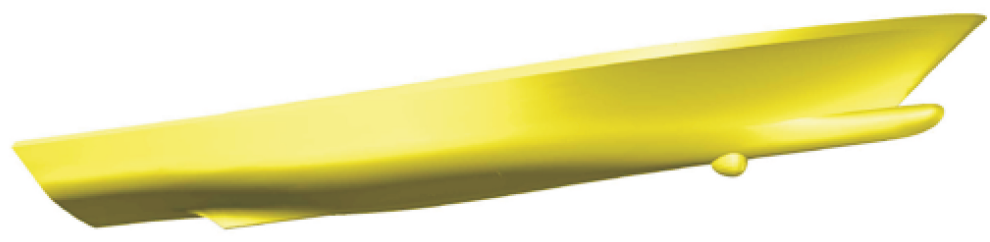

Fig. 2. 3D hull model view 
Table 2. Main particulars of hull

\begin{tabular}{|l|c|c|}
\hline Non-dimensional hull data & Symbol & Values \\
\hline Length to beam ratio & $L_{p p} / B$ & 6.269 \\
\hline Beam to draft ratio & $B / T$ & 3.395 \\
\hline Rudder lateral area & $A_{R} / L T$ & 0.011 \\
\hline Block coefficient & $C_{B}$ & 0.460 \\
\hline Number propellers & {$[-]$} & 2 \\
\hline Number rudders & {$[-]$} & 2 \\
\hline
\end{tabular}

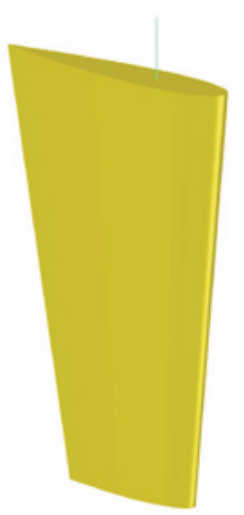

Fig. 3. Rudders geometry

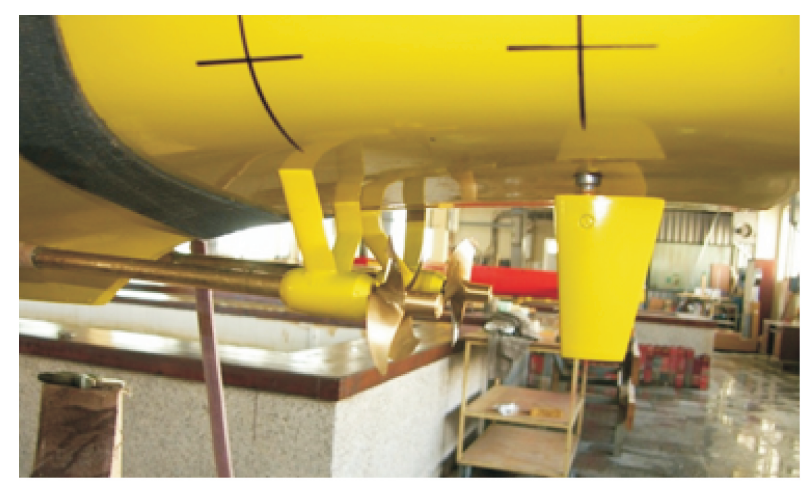

Fig. 4. View of rudder - propeller arrangement

Table 3. Rudder model data

\begin{tabular}{|l|c|c|c|}
\hline Characteristic & Symbol & Dimension & Model \\
\hline Area & $A_{R}$ & $\mathrm{~m}^{2}$ & 0.00545 \\
\hline Height & $h_{R}$ & $\mathrm{~m}$ & 0.10160 \\
\hline Mean chord & $b_{R}$ & $\mathrm{~m}$ & 0.05370 \\
\hline Profile & & NACA 0019 & \\
\hline
\end{tabular}

The manoeuvring model tests are carried out in BSHC Manoeuvring \& Seakeeping Basin at initial steady speed, deep calm water and constant revolutions, Figs 5 and 6 . 


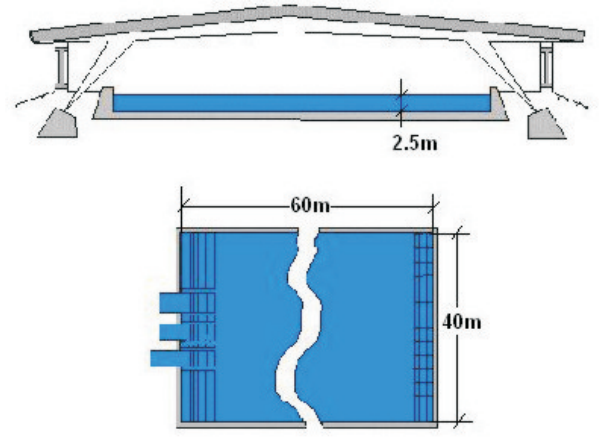

Fig. 5. BSHC Manoeuvring basin main dimensions

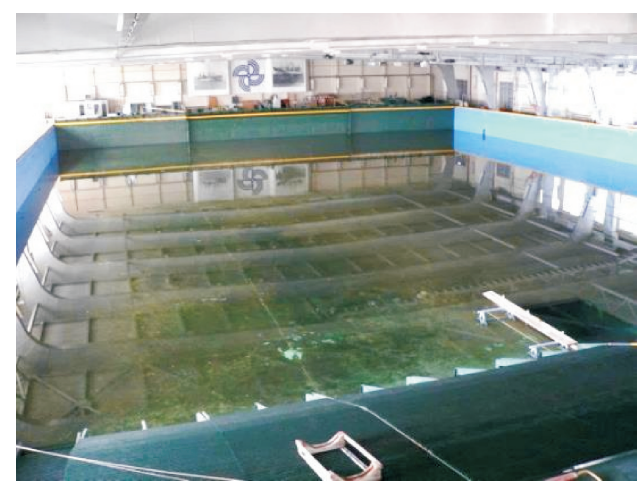

Fig. 6. BSHC Manoeuvring basin

Model equipment

The equipment needed for free-running tests is into two groups: on-board and onshore equipment, synchronized by a radio link. The on-board equipment contains all necessary units for remote controlling of the model, as well as for measurements, data acquisition and data recording. The rudder force dynamometer allows measurement of the tangential $\left(F_{X}\right)$ and normal $\left(F_{N}\right)$ forces and torque in rudder fixed coordinate system, Fig. 7.

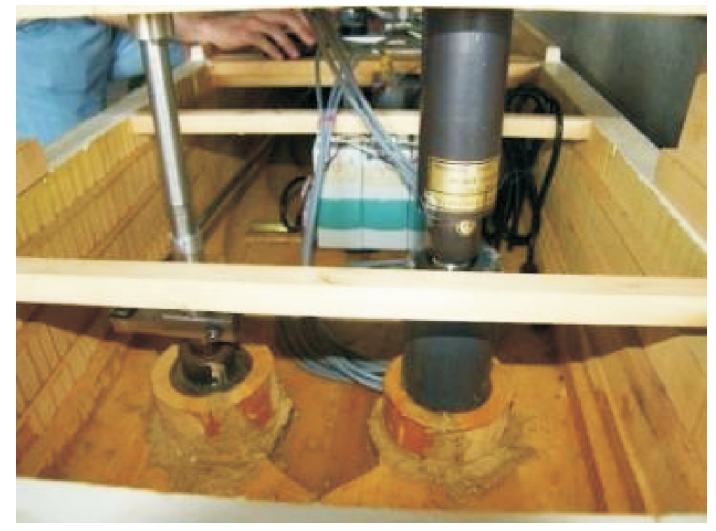

Fig. 7. Rudder force dynamometer

\subsection{Experimental results for the asymmetric efficiency of the units of twin rudder system by free-running model manoeuvring tests}

The measured time-series of tangential $F_{X}$ and normal $F_{N}$ rudder forces are shown in Fig. 8, [2]. 

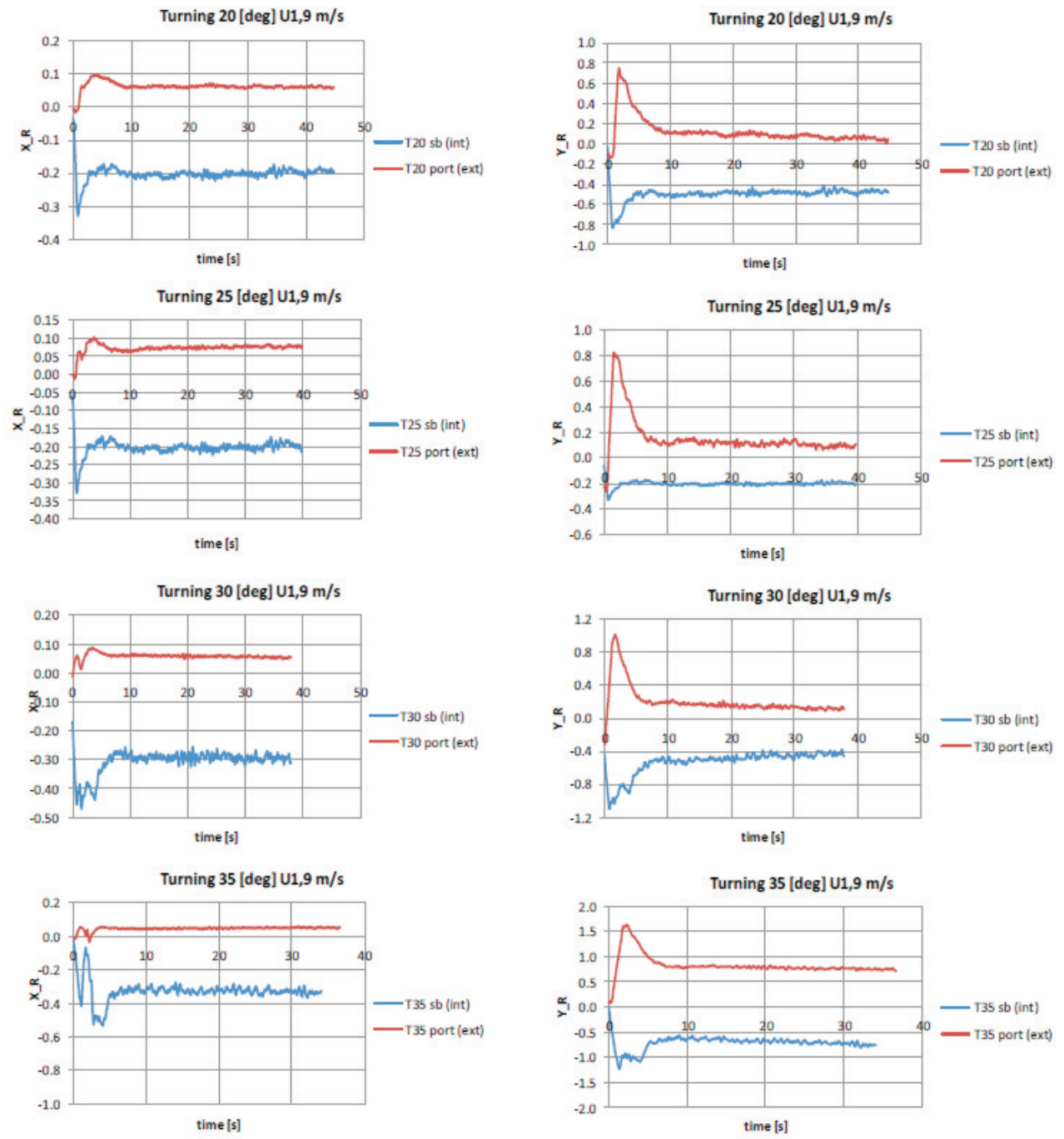

Fig. 8. Tangential $F_{X}[\mathrm{~N}]$ (left) and normal forces $F_{N}[\mathrm{~N}]$ (right) for the internal (int) and external (ext) rudders in turning circle manoeuvre with speed $F_{r}=0.34$

Based on the figures, it can be concluded that the tangential force to the external rudder is slightly affected by the angle of attack, only small peak values are observed during its deflection. In the same time range, this force to the internal rudder is much greater, with clearly expressed peak values at the unsteady stage of the manoeuvre. The normal rudder force $F_{N}$ also increases in a similar way, but the difference between the two rudder loads is bigger [3]. 
The spacing could affect to the interaction into the twin rudder configuration which effects to its hydrodynamic characteristics, i.e. lift and drag. Despite this, the hydrodynamic coefficients in this configuration are commonly assumed equal for both rudders although they are actually different for each one. However, it is not explicitly considered in existing empirical formulae used for estimation of rudder behaviour.

\section{DETERMINATION AND ANALYSIS OF THE HYDRODYNAMIC INTERACTION COEFFICIENTS AT THE TR SYSTEM}

\subsection{Numerical estimation of impact of the spacing to TR system efficiency by CFD}

A series of CFD computations are conducted by the solver "ANSYS Fluent 18.1-Academic", the analyses use a $k-\omega$ SST turbulence model and a pressurebased coupled algorithm. Furthermore, the size of the domain should be as large as possible - it is $20 C_{R}$ long and $30 C_{R}$ wide. The mesh is designed by the Assembly Meshing Method, it is accessible only when Physics and Solver Preferences are set to CFD and Fluent, respectively. It generates a majority of hex cells and performs boolean operations. Hex Meshing is best suited for CFD. Some wedges, tets and pyramids are generated at the boundaries to capture the geometry. The elements must be aligned in direction of flow. It reduces element count, run time and numerical error, respectively. The quality criterion is the Orthogonal Quality which recommends values for Cutcell meshes up to 0.1 (in the presented cases is 0.101) - Table 4, Fig. 9. Acceptable accuracy was reached within the mesh size of $4.5 \mathrm{mln}$ elements, and 10 prism layers were created around the body by using the equidistance law for better near wall flow modelling.

The aim is to be studied the impact of the spacing of twin-rudder configuration to its hydrodynamics. These aspects could be reason for the rudder asymmetric behaviour with regard to manoeuvring and propulsion [26-27].

A regression model for prediction of the rudders lift coefficient into the twin rudder configuration at "open-water" is developed based on the results. The relative positions of the rudders are defined by the lateral spacing between the rudder stocks $\left(Y_{T R}\right)$, and the rudder chord length $\left(C_{R}\right)$ is used as nondimensional factor. 


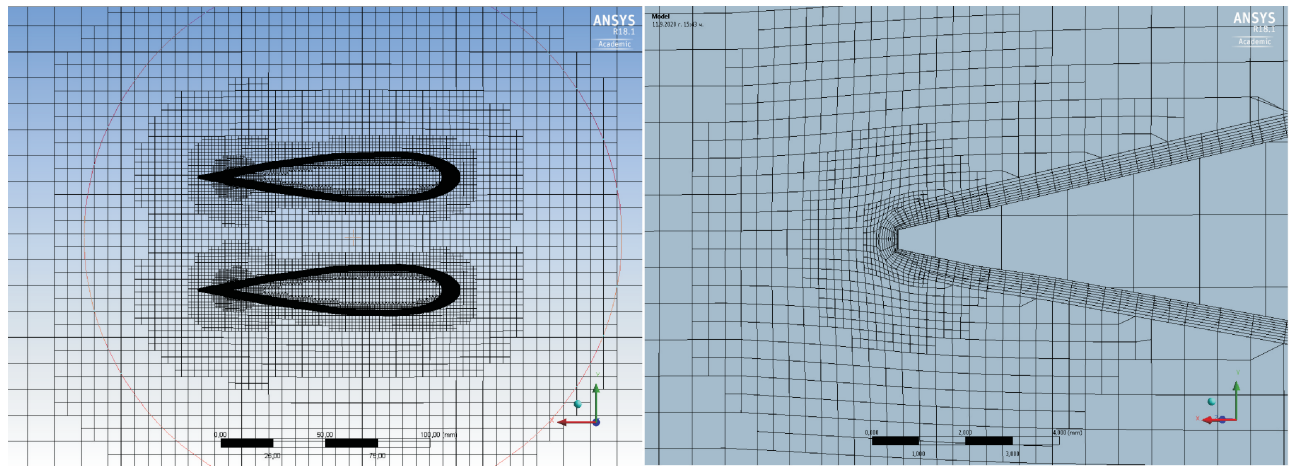

Fig. 9. Applied cut-cell mesh that fills the domain and the inflation

Table 4. CFD Test matrix

\begin{tabular}{|c|c|c|c|c|c|c|}
\hline Profile & Configuration & $R_{n}$ & $Y_{T R}[\mathrm{~mm}]$ & $Y_{T R} / C_{R}$ & $\begin{array}{c}\text { Rudder } \\
\text { angle [deg] }\end{array}$ & $\begin{array}{c}\text { Measured } \\
\text { forces }\end{array}$ \\
\hline NACA & single & \multirow{2}{*}{$2.1^{*} 10^{5}$} & 182 & 3.4 & 25,20, & Drag \\
0019 & twin & & 54 & 2 & 19,15, & Lift \\
\hline
\end{tabular}

\subsubsection{Test matrix and twin rudder configurations}

The experimental program includes the original distance between the rudder stocks $\left(Y_{T R}\right)$, according to the conducted model tests and two cases of reduced distance, in order to detect the critical spacing. The motion in "open-water" with high speed at different angles of attack is simulated, so that the rudders asymmetric effectiveness for the corresponding $Y_{T R}$ can be determined.

Two equations turbulence model is used because it allows the steady state simulations to be performed and gives some advantages:

- Shorter simulation time;

- Simplified post-processing;

- Time averaged values of studied quantities are produced.

In turn $k-\omega$ SST model was preferred due to its better performance than $\mathrm{k}-\varepsilon$ models for boundary layer flows prediction [17]. In this case for better boundary layer estimation the first mesh cell centroid is placed at $y^{+} \sim 1$, so that it enters the viscous sublayer where $y^{+}$is dimensionless wall distance:

$$
y^{+}=\frac{y u_{\tau}}{\nu},
$$

where $u_{\tau}$ is the friction velocity, $\nu$ - viscosity. 
The mesh size of the domain is tested by using Richardson extrapolation approach which brings into action the following, Fig. 10 [15]: If the formal rate of convergence of discretization method is known, and if the numerical solutions of two systematically improved meshes are known, then it is possible to use the available information to obtain the exact solution of the mathematical model:

$$
g_{h}=f_{h}-f^{*}=g_{2} h^{2}+g_{3} h^{3}+O\left(h^{4}\right),
$$

where $f_{h}$ is the exact solution of numerical equations and $f^{*}$ is the exact solution of partial differential equations.

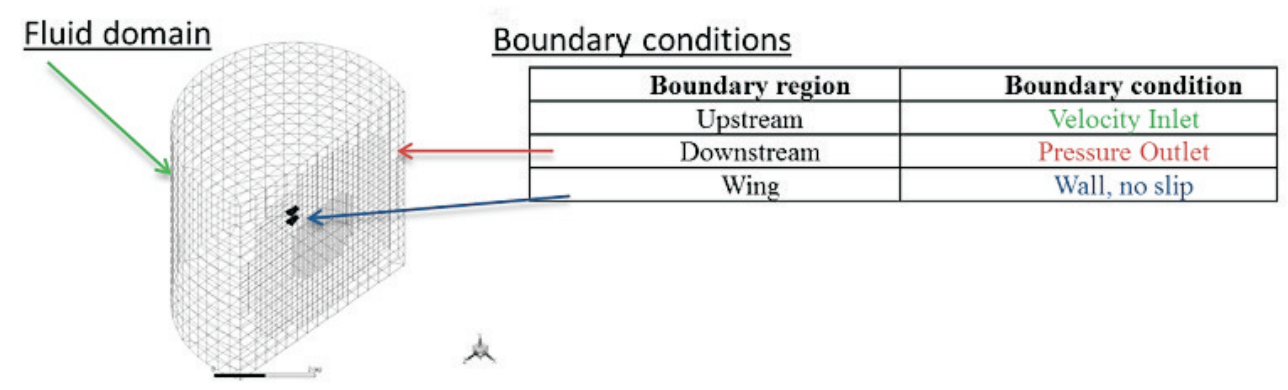

ANSYS: sst $k-\omega$

Fig. 10

\subsubsection{Research results of the impact of the spacing to the twin rudder effectiveness by $C F D$ method}

The visualization of the stream flow of twin rudder in "open-water" and various $Y_{T R}$ is carried out, Fig. 11, and for verification it is also made on a single rudder, Fig. 12 [2].

There is no visible difference in flow between the cases of single rudder and the twin rudders with distance $Y_{T R} / C_{R}=3.4$ and 2.0. It is noticed that $Y_{T R} / C_{R}=1.0$ is critical, the asymmetric operation of both units of TR is visible at large angles of deviation. At 19 degrees and bigger Angles of Attack (AoA), a flow separation is observed at the outer (right) rudder due to its deviation to the port side.

From the comparison between the calculated drag and lift forces of each of the rudders it is seen that at the large distances between them $\left(Y_{T R} / C_{R}=\right.$ 3.4 and 2.0), their effectiveness is equivalent to a single rudder, i.e. there is no 
interaction between the units of the twin rudders, and no influence through the relative distance $Y_{T R} / C_{R}$, Fig. 13.

At $Y_{T R} / C_{R}=1.0$, the results show clear asymmetric efficiency. The internal (left) rudder has increased drag, but also increased lift compared to the cases $Y_{T R} / C_{R}=3.4$ and 2.0. In the external (right) rudder, there was about 5 times lower drag but also a lower lift with a failure in the critical angle of 15 degrees - about 3 times compared to the other two cases.

For the critical case $Y_{T R} / C_{R}=1.0$, it can be summarized that at the internal (left) rudder its lift force increases constantly monotonically even after 15 degrees, but the same applies to its friction - it is steadily increasing. At the external (right) rudder has a significant decrease in its drag, but even more significant at its lift.

Appropriate assessment of the character of the efficiency of the twin rudders at different relative distances is given by the efficiency criterion for the rudders CL/CD and $C L_{\text {twin/single }}$ [27-28]. A second comparison to how far the twin rudder is effective against a single rudder, considering the obtained almost identical forces for $Y_{T R} / C_{R}=3.4$ and 2.0. At both coefficients it is evident that the critical distance for a twin rudder is $Y_{T R} / C_{R}=1.0$ and their effectiveness is impaired in the field of small deviation angles to 15 degrees:

$$
C_{\text {Ltwin }}=\left(L_{L}+L_{R}\right) /\left((\rho / 2)^{*} V^{2 *} 2^{*} A\right) .
$$
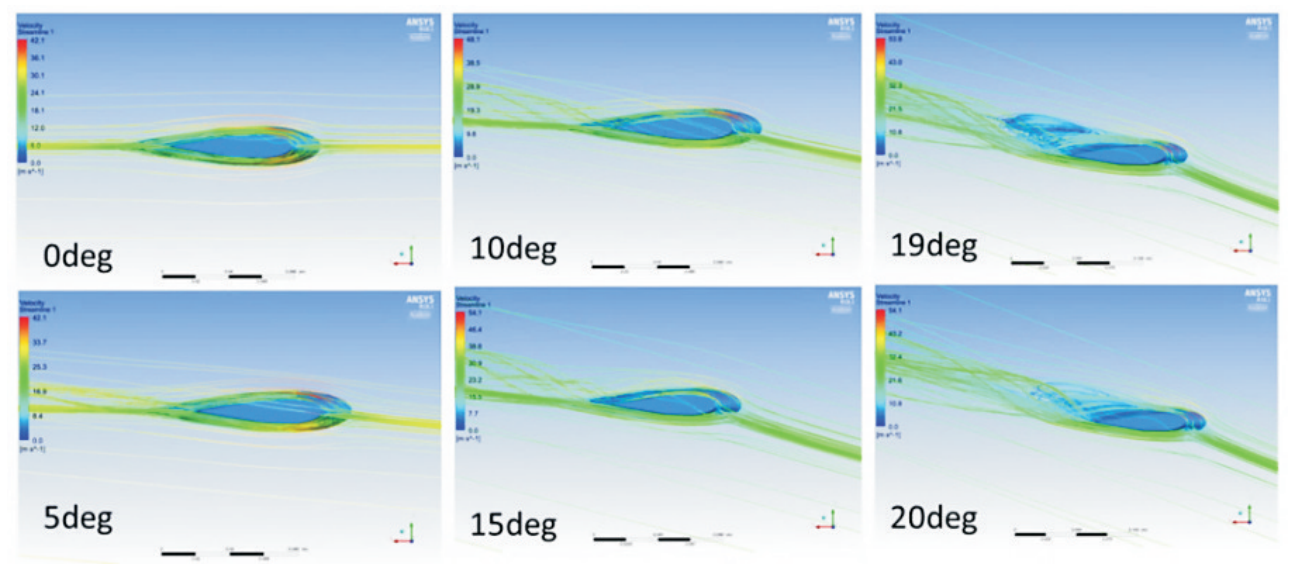

(a)

Fig. 11. (a) Visualization of the stream flow of a single rudder at "open water" 

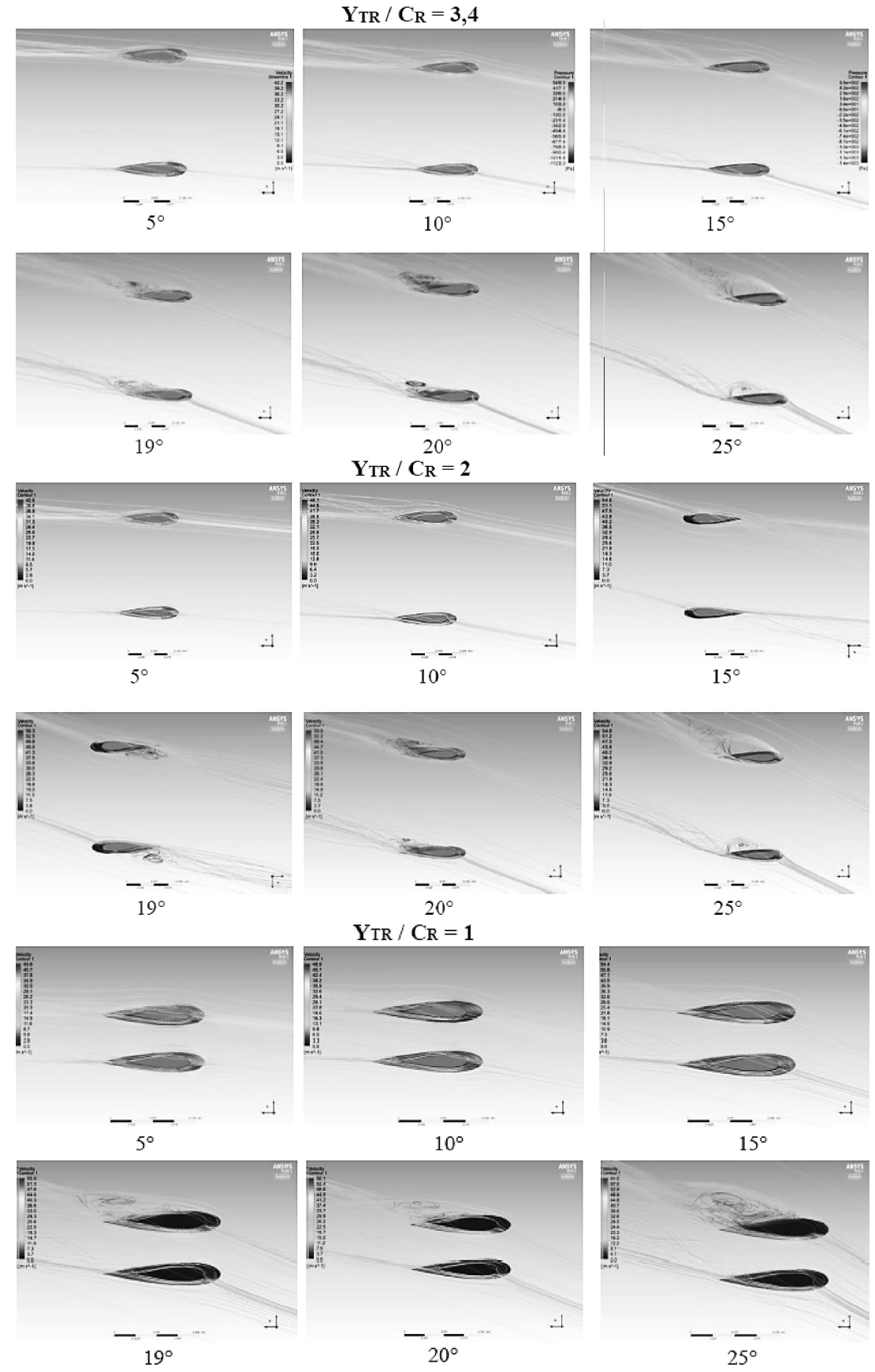

(b)

Fig. 11. (b) Visualization of the stream flow of a twin rudder in "open-water" and various $Y_{T R}$ 

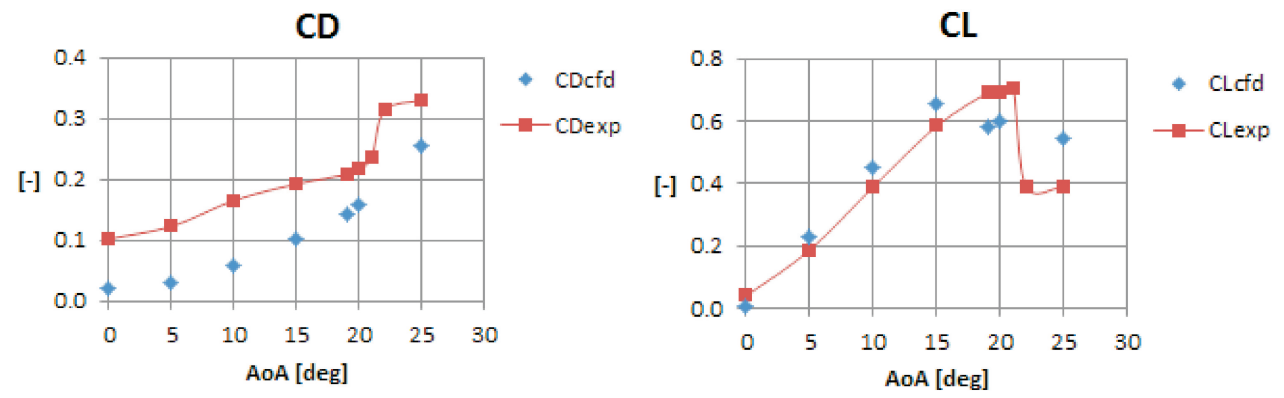

Fig. 12. Drag and lift coefficients of a single rudder in "open-water" by wind tunnel test and CFD
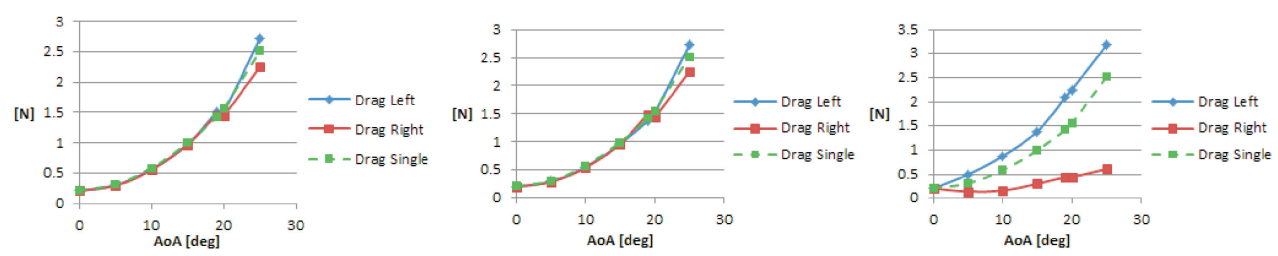

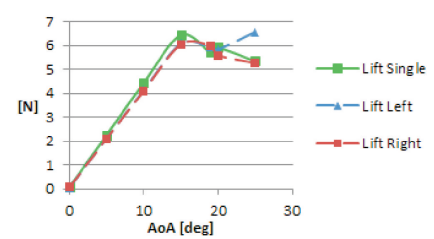

(a)

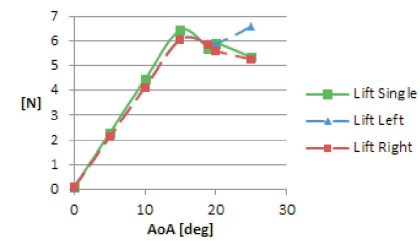

(b)

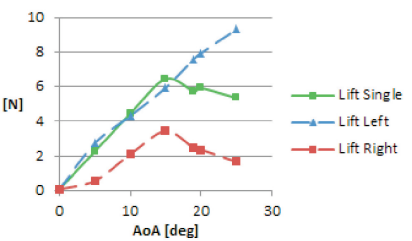

(c)

Fig. 13. Drag and lift forces for a single rudder and each unit of the twin rudders at varied relative distances and AoA: (a) $Y_{T R} / C_{R}=3.4$; (b) $Y_{T R} / C_{R}=2$;

(c) $Y_{T R} / C_{R}=1$

\subsection{Analysis of impact of the spacing to the TR system efficiency by CFD}

Considering the nature of the CL/CD analysis of the effectiveness of the twin rudders is made, if the deflection of the external (right) rudder to the internal (left) board is limited to 15 degrees. The results show that it is possible to improve the overall performance of the twin rudders in the range of large angles of attack, with a slight decrease in drag and a clearly visible improvement in the generated lift, Fig. 14.

The results lead to the idea of a possible prediction of the impact of the relative distance between the units of twin rudders on its overall work. A 
regression analysis is made based on the $C L_{\text {twin/single }}$ dependence in order to create an approach to predicting the limit value of the relative distance between the rudder stocks of twin rudders, which will not reduce its overall performance, Fig. 15. Figures 16 and 17 show polynomial expressions describing the total change of its coefficients referring to each relative distance presented in Fig. 15.
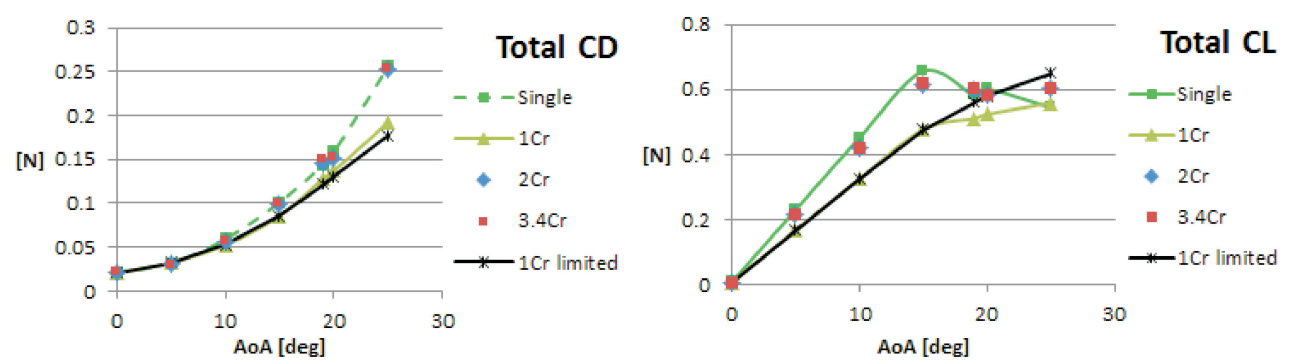

Fig. 14. The twin rudder total drag and lift coefficients with a limited deflection to 15 degrees of the external (right) rudder to the internal (left) board
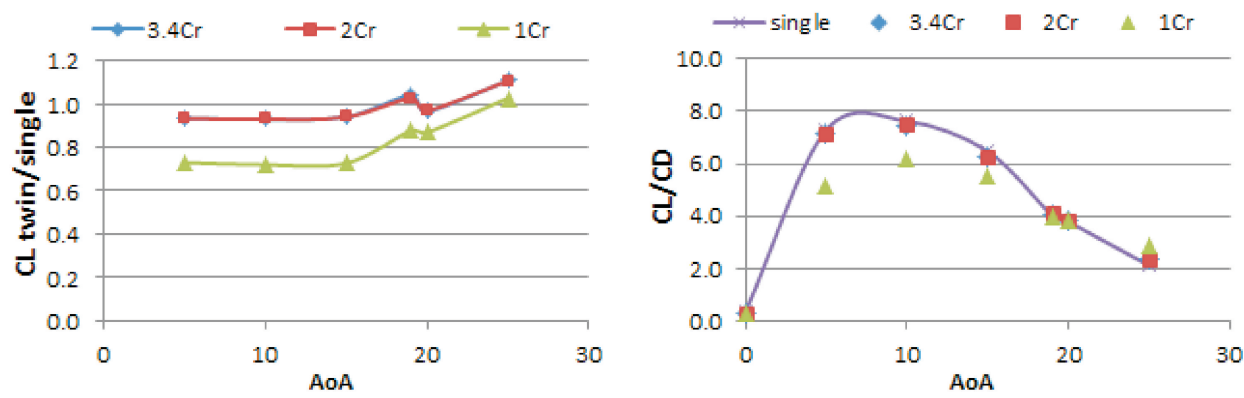

Fig. 15. Impact of the relative spacing between the units of twin rudders to its efficiency criterion (right) and its total lift against a single rudder (left)

A regression equation is constructed to determine the relative change in the created total lift force by twin rudders according to a single rudder for the respective $Y_{T R} / C_{R}$, as a function of the rudders angle:

$$
C L_{\text {twin } / \text { single }}=a^{3} * \delta^{2}-a^{2} * \delta+a .
$$

The results from the variation of rudder angles for different $C_{R}$ in the above expression show a slight influence of the deflection angle to $C L_{t w i n / s i n g l e}$. 

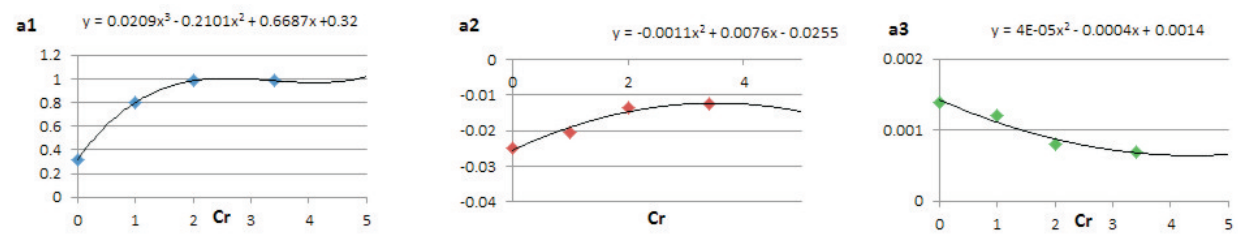

Fig. 16. Polynomial dependencies as a function of $Y_{T R} / C_{R}$

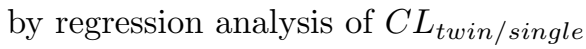

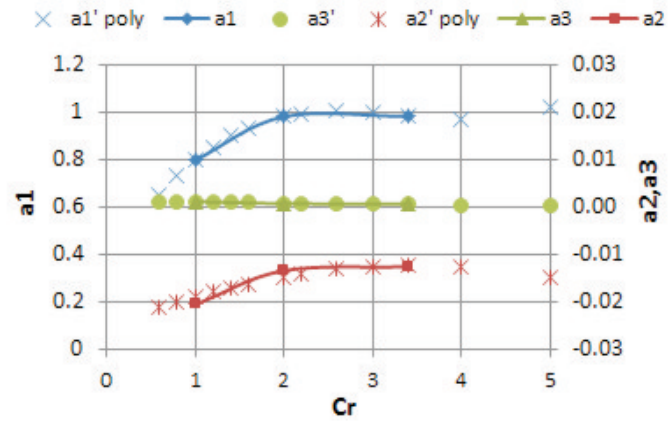

Fig. 17. Polynomial coefficients to the regression equation for $Y_{T R} / C_{R}$

This allows summarizing by averaging $C L_{\text {twin/single }}$ for all angles at the corresponding $Y_{T R} / C_{R}$. Based on the described approach, the dependence of $C L_{\text {twin/single }}$ is graphically determined as a function of $Y_{T R} / C_{R}$, Fig. 18 .

In the graphs it is seen that there is no reduction of the lift coefficient of the twin rudders relative to a single rudder in the range of large distances $C_{R}=2-5$, they are even identical. Since in the range $C_{R}=2-5$, an impact of the TR system spacing in "open-water" is missing, its total lift must be equal to the doubled lift of the same single rudder in "open-water". The Prandl's well-known formula gives the possibility of predicting the lift force of single NACA profile up to its stall angle - in this range the derivative $C_{L}^{\alpha}$ is linear:

$$
C_{L}^{\delta}=\frac{2 \pi \lambda}{2+\lambda} * \delta
$$

where aspect ratio $\lambda=h_{R} / b_{R}$.

For $Y_{T R}<2 C_{R}$, the efficiency decreases $C L_{\text {twin/single }}<1$, i.e. the $C L$ coefficient of the twin rudders is lower than of the single rudder due to poor interaction. For these kind cases the function of $C L_{t w i n / s i n g l e}$ is used - pre- 

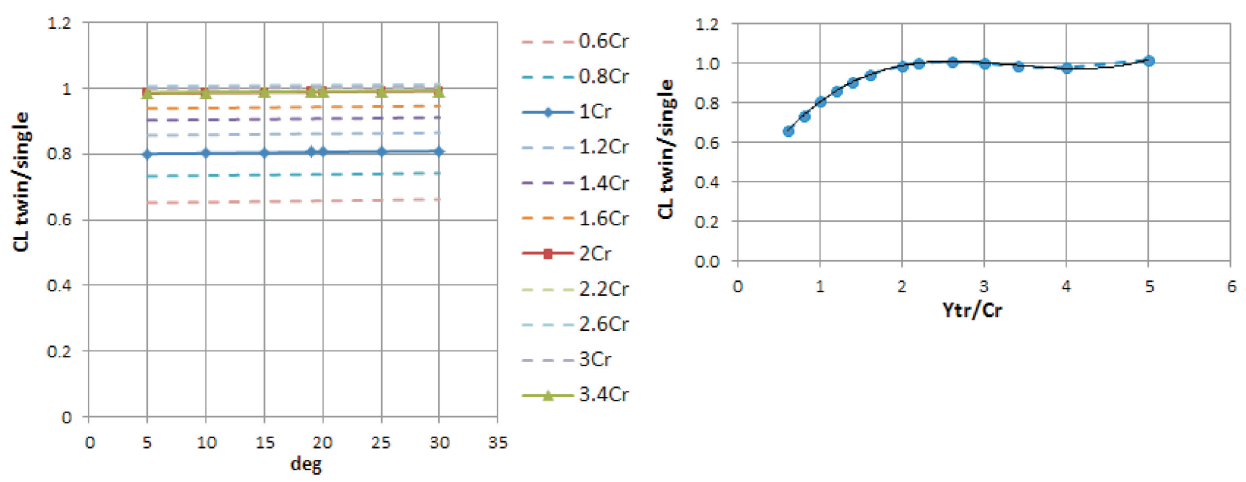

Fig. 18. Influence of the angle of attack (left) to $C L_{\text {twin/single }}$

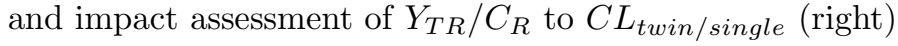

diction of the impact of the TR system spacing to its efficiency:

$$
C L_{t w i n}=2 * \frac{2 \pi \lambda}{2+\lambda} * \delta * C L_{t w i n / s i n g l e} .
$$

\section{CONCLUSION}

$\gg$ The study shows an asymmetric efficiency of the rudders at TPTR system of fast patrol ship in curvilinear manoeuvres. Externally located rudder according to the side on which the curvilinear manoeuvre is performed is in risk of loss of efficiency. If it would be possible technical limitation of the rudder deflection to its critical angles, this effect could avoid. For conventional ships, which have a large displacement and less efficient rudders at a relatively low flow rate, it will be of great benefit to increase the efficiency of their rudder systems;

$\gg$ The impact of the twin rudder distance to its efficiency is evaluated and analysed by the CFD and the ANSYS solver. For the considered case, the critical distance value between the rudders is determined, at $Y_{T R}<2 C_{R}$ its total lifting force strongly decreases;

$\gg$ Based on the results from the numerical study obtained by the solver "ANSYS Fluent 18.1-Academic", a regression analysis is performed and a polynomial expression is compiled determining the relative influence of the $Y_{T R}$ distance to the lift created by the twin rudder $-C L_{t w i n / s i n g l e}$, for the respective $C_{R}$ as a function of rudder deflection angle: 


$$
C L_{\text {twin } / \text { single }}=a^{3} * \delta^{2}-a^{2} * \delta+a ;
$$

$\gg$ The described influence between the twin rudder lift force and the distance between the rudders should be considered more detail for different rudder profiles or their series in order to be defined the application limits of the polynomial expression. Based on the Prandl's well-known formula, such a study can make possible to predict the lift of twin rudders according to their distance $Y_{T R}$ and angle of deflection.

\section{REFERENCES}

[1] Guidance for Naval Surface Ships Mission Oriented Manoeuvring Requirements, NATO Allied Naval Engineering Publication 70 (2003) I.

[2] D. Efremov and E. Milanov, Investigation of Twin-rudder Load Asymmetric Behaviour by Free-running Model Tests, in: Twenty First International Conference on Hydrodynamics in Ship Design and Operation, HYDRONAV'2017, Gdansk, Poland, 28-29 June, 2017.

[3] S. Khanfir, K. Hasegava, V. Nagarajan, K. Shouji, and S. Keon Lee, Manoeuvring Characteristics of Twin-rudder Systems: Rudder-Hull Interaction Effect on the Manoeuvrability of Twin-rudder Ships, Journal of Marine Science and Technology (2011) 472-490.

[4] S. Khanfir, K. Hasegawa, E. Kobayashi, and V. Nagarajan, Mathematical Model for Manoeuvring of Twin-propeller Twin-rudder Ship Considering Peculiar Rudder Normal Force Phenomenon, in: MARSIM, Singapore, 2012, 1.

[5] J. Liu and R. Hekkenberg, Interaction Effects on Hydrodynamic Characteristics of Twin Rudders, in: International Conference on Maritime Technology, ICMT'2016, Harbin, China, 2016.

[6] J. Liu, Y. Wang, F. Ma, And S. Li, Impacts of Rudders on the Performance of a Benchmark Inland Vessel in the Rhine, International Conference on Marine Simulation and Ship Manoeuvrability, MARSIM'2018, Halifax, Canada, 2018.

[7] A. F. Molland and S. R. Turnock, Marine Rudders and Control Surfaces, Elsevier, London, UK (2007).

[8] M. Viviani, C. Bonvino, S. Mauro, M. Cerruti, D. Guadalupi, and A. Menna, Analysis of Asymmetrical Shaft Power Increase during Tight Manoeuvres, FAST, Shanghai, China, 2007.

[9] V. Ankudinov and B. Jakobsen, Physically Based Manoeuvring Model for Simulations and Test Evaluation, in: International Conference on Marine Simulation and Ship Manoeuvrability MARSIM'2006, Terschelling, Netherlands.

[10] V. G. Sobolev, Ship Handling and Navigation Automation, Shipbuilding (1976) (in Russian). 
[11] H. Thieme, Design of Ship Rudders, David Taylor Model Basin, USA (1965).

[12] S. R. TuRnock, Prediction of Ship Rudder-propeller Interaction Using Parallel Computations and Wind Tunnel Measurements, Ph. D. Thesis, University of Southampton (1993).

[13] A. V. Vasiliev, Ship Handling, Shipbuilding, Leningrad (1989) (in Russian).

[14] K. K. Fedyaevsky and V. G. Sobolev, Ship Handling, Sudpromgiz (1963) (in Russian).

[15] L. Richardson and A. Gaunt, The Deferred Approach to the Limit, Philosophical Transactions of the Royal Society of London, Series A 226 (1927).

[16] A. Coraddu, G. Dubbioso, S. Mauro, and M. Viviani, Analysis of Twin Screw Ships Asymmetric Propeller Behaviour by Means of Free Running Model Tests, Ocean Engineering (2013) 68 47-64.

[17] D. C. Wilcox, Turbulence Modelling for CFD, DCW Industries, Inc. La Canada, California (1998).

[18] G. Dubbioso and M. Viviani, Aspects of Twin Screw Ships Semi-empirical Manoeuvring Models, Ocean Engineering (2012) 48 69-80.

[19] G. Dubbioso and M. Viviani, Experimental Investigation of Asymmetrical Propeller Behaviour of Twin Screw Ships during Manoeuvers, in: MARSIM'2012, Singapore (2012) 1.

[20] G. Dubbioso, S. Mauro, and M. Viviani, Off-design Propulsion Power Plant Investigations by Means of Free Running Manoeuvring Ship Model Test and Simulation Techniques, in: Proceedings of the $21^{\text {th }}$ International Offshore and Polar Engineering Conference, Hawaii, USA, 2011.

[21] A. D. Goffman, Propulsion and Steering Complex and Manoeuvring the Vessel, Shipbuilding (1988) (in Russian).

[22] D. Efremov, Simulation Model of the "Main Engine-Hull-Propeller" System Dynamics in Ship Manoeuvring Motion, Ph. D. Thesis, BSHC-BAS (2015) (in Bulgarian).

[23] Y. I. Voitkunsky, Yu. I. Faddeev, and K. K. Fedyaevsky, Hydromechanics, Shipbuilding, Leningrad (1982) (in Russian).

[24] D. Efremov, Experimental Investigation of Asymmetric Behaviour of Propeller Shafts during Manoeuvring of Twin Screw Ship, Engineering Sciences (2016) LIII (4) 63-77, ISSN 1312-5702.

[25] A. M. Basin, Propulsion and Handling of Ships, Moscow, Transport (1977) (in Russian).

[26] Hydrodynamic Characteristics of Ship Rudders (atlas), Novosibirsk Engineers Institute of Water Transport (1972) Issue 72 (in Russian).

[27] Lui Jialun, Robert Hekkenberg, Erik Rotteveel, and Hans Hopman, Hydrodynamic Characteristics of Multiple-rudder Configurations, Ships and Offshore Structures (2017) 12 (6) 818-836, DOI: 10.1080/17445302.2016.1275472. 
[28] S. Khanfir, K. Hasegava, V. Nagarajan, K. Shouji, and S. Keon Lee, Estimation of Mathematical Model and Its Coefficients of Ship Manoeuvrability for a Twin Propeller-Twin Rudder Ship, in: Proceedings of MARSIM'09, Panama City, 2009, pp. 159-166.

Received April 05, 2021 